\title{
A Comprehensive Review on the Pharmacological Activity of Schiff Base Containing Derivatives
}

\author{
Joginder Kumar, Amit Rai and Vinit Raj* \\ Department of Pharmaceutical Sciences, Babasaheb Bhimrao Ambedkar University, India
}

Submission: December 15, 2016; Published: January 23, 2017

*Corresponding author: Vinit Raj, Department of Pharmaceutical Sciences, Babasaheb Bhimrao Ambedkar University, Vidya Vihar, Rai Bareli Road, Lucknow-226025, India; Tel: +918859383897; Email: raj.vinit24@gmail.com

Abstract

The chemistry of Schiff base containing, compounds have been an interesting field of study from ancient years. Subsequently, Schiff base constitutes a significant class of compounds for new drug development. Recently, various Schiff base containing derivatives have been synthesized and evaluated for their biological activities including as antimicrobial, anti-tuberculosis, antioxidant, anti-inflammatory, anticonvulsants, antidepressant and anxiolytic, antihypertensive, anticancer and antifungal activity. The search for Schiff base containing compounds with more selective activity and lower side effect continues to be an active area of argument examination in medicinal chemistry. This review is ornately pronounced the medicinal chemistry, their biological properties.

Keywords: Schiff base; biological activity; method of synthesis; Applications of Schiff base transition metal complexes; hydrazones

\section{Introduction}

A Schiff base, named after Hugo Schiff, is a compound with a functional group that contains a carbon-nitrogen double bond with the nitrogen atom connected to an aryl or alkyl group, not hydrogen [1]. Schiff bases in a broad sense have the general formula

\section{$\mathrm{R} 1 \mathrm{R} 2 \mathrm{C}=\mathrm{NR} 3$,}

where $\mathrm{R}$ is an organic side chain. In this definition, Schiff base is synonymous with azomethines. Some restrict the term to the secondary aldimines (azomethines where the carbon is connected to a hydrogen atom), thus with the general formula

\section{$\mathrm{RCH}=\mathrm{NR}^{\prime}[2]$.}

The chain on the nitrogen makes the Schiff base stable imines. A Schiff base derived from aniline, where R3 is a phenyl or a substituted phenyl [3].

Schiff bases are formed when any primary amine reacts with an aldehyde or a ketone under specific conditions. Structurally, a Schiff base (also known as an imines or azomethines) is a nitrogen analog of an aldehyde or ketone in which the carbonyl group $(\mathrm{C}=0)$ has been replaced by an imines or azomethines group. Schiff bases are some of the most widely used organic compounds. We also highlight the most significant examples of compounds belonging to this class, which exhibit analgesic, anti- inflammatory, antimicrobial and non-ulcerogenic activities to have been reported in the literature [4](Figure 1).

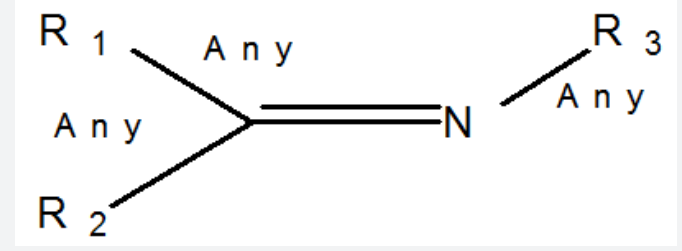

Figure 1: General structure of a Schiff base.

Schiff bases are crystalline or oily substances that are insoluble in water and soluble in organic solvents. They are weak bases, forming salts with acids in an anhydrous medium; in aqueous acid solutions, they undergo hydrolysis to yield an amine and aldehyde. The majority of Schiff bases are stable in alkaline solutions. Schiff bases are valuable intermediate products of organic synthesis, for example, in the preparation of secondary amines and various heterocyclic compounds. The Schiff bases known as azomethines dyes are used for dyeing acetate and synthetic fibers; they are also used in color photography to reduce the photosensitivity of photographic emulsions [5]. Schiff base metal complexes have been studied extensively because of their attractive chemical and physical properties and their wide range of applications in numerous scientific areas. These types 


\section{Organic and Medicinal Chemistry International Journal}

of complexes have been vigorously explored in recent years and such studies have been the subject of many papers and reviews. Many of them are centered on the catalytic activity of Schiff base complexes in a large number of homogeneous and heterogeneous reactions.

\section{Synthesis of Schiff base}

Schiff bases can be synthesized from an aromatic amine and a carbonyl compound by nucleophilic addition forming a hemiaminal, followed by a dehydration to generate an imines. In a typical reaction, 4, 4,-diamino diphenyl ether reacts with o-vanillin [6](Figure 2).

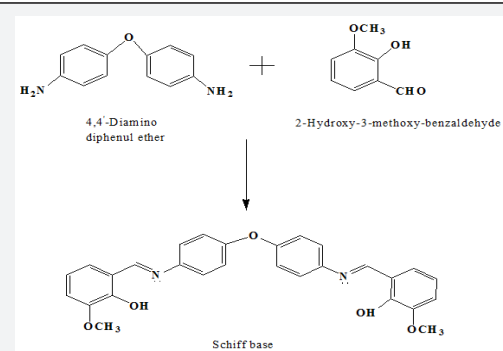

Figure 2: Synthesis of Schiff base.

\section{Synthesis of Schiff base from Aldehydes and Ketones}

The first step of the mechanism generates a carbocation. This reacts with the lone pair of electrons on the nitrogen in the amine. The unstable product of this step is stabilized by the loss of an equivalent of water from the molecule, to form a Schiff base as shown below (Figures $3 \& 4$ ). Actually another name for an imines functional group, in biochemistry a Schiff base is formed by the condensation of an amine group with the carbonyl group of an aldehyde or ketone. Since the nitrogen of the resulting bond has basic character (indicated by the lone pair shown explicitly on the nitrogen atom in the (Figure 5) it can take up a proton to form the conjugate acid of the Schiff base, or the protonated Schiff base. The formation of a Schiff base and its functionality are important in the mechanism of a number of enzymes, including that of aldolase and those, like aminotransferases, using pyridoxal phosphate as a cofactor.

$$
\begin{aligned}
& \mathrm{R}_{3}-\ddot{\mathrm{NH}}_{2}+\mathrm{O}=\mathrm{C}_{\mathrm{R}_{2}}^{\mathrm{R}_{1}} \longrightarrow \mathrm{R}_{3}-\ddot{\mathrm{N}}=\mathrm{C}_{\mathrm{R}_{2}}^{\mathrm{R}_{1}}+\mathrm{H}_{2} \mathrm{O} \\
& 1^{0} \text { Amine Aldehyde OR Ketone Schiff Base }
\end{aligned}
$$

Figure 3: Synthesis of Schiff base from Aldehydes and Ketones

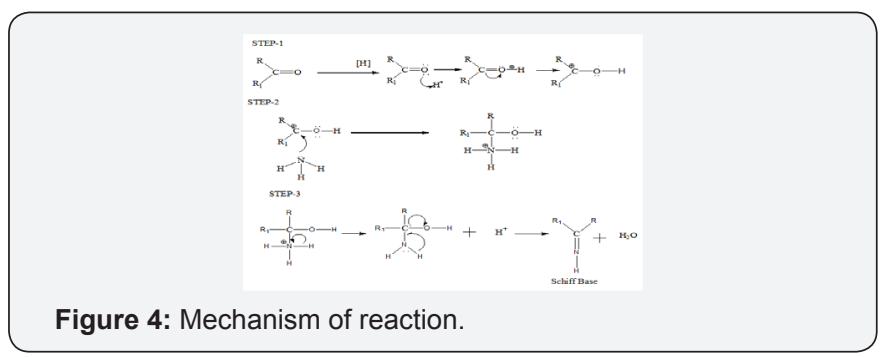

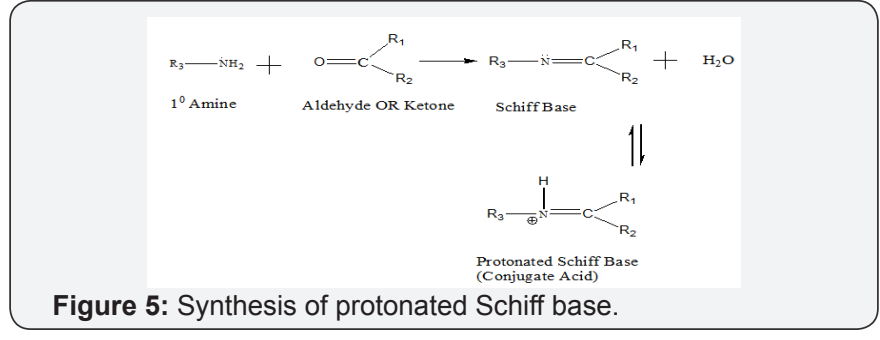

In general, the primary amine is the amino group of a lysine residue. Another important example of the biological function of a Schiff base is provided by bacteriorhodopsin, a light-driven proton pump. The reversible protonation of the Schiff base is central to the proton pumping mechanism of this remarkable energy-transducing molecule. The (Figure 6) below shows a plausible scheme for the formation of a Schiff base in the context of the active site of an enzyme. Basic groups on the enzyme are represented as B-Enz, and acidic groups as +HBEnz. It is important for the amine in this mechanism to be in its unprotonated, basic form since it is the nucleophile attacking the electrophilic carbonyl carbon. A protonated amine would not act as a nucleophile. The intermediate produced in the first step is termed a carbinolamine. Note also that the scheme is shown results in the direct production of the protonated form of the Schiff base [7].

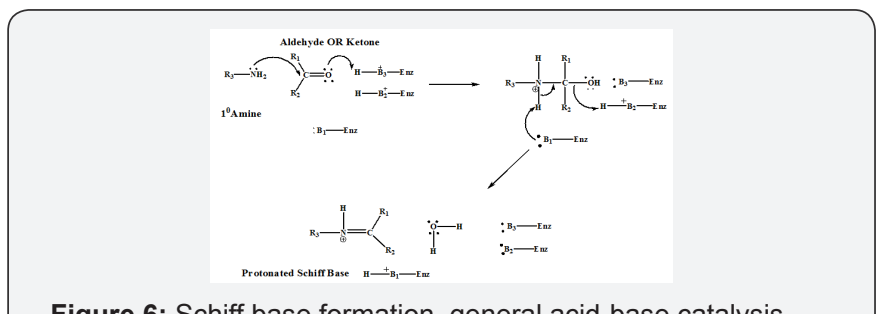

Figure 6: Schiff base formation, general acid-base catalysis.

\section{Hydrazones}

are close relatives to imines, but are not abundantly in biological molecules. Hydrazones are formed in reactions between aldehydes/ketones and hydrazines, a functional group containing a nitrogen-nitrogen bond (Figure 7).

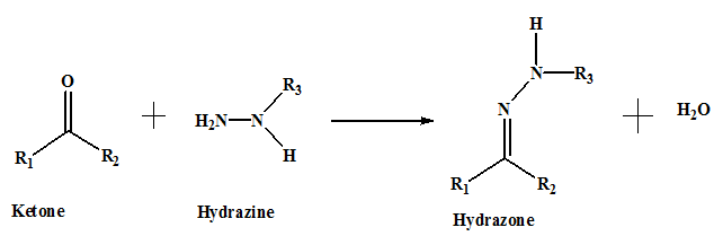

Figure 7: Schiff base formation in aldolase reactions.

Another important example of Schiff base formation in biological chemistry involves carbon-carbon bond-forming reactions catalyzed by enzymes called aldolase. In an aldol reaction, two carbonyl-containing compounds condense to form a single molecule. A key step in this process is the formation of a Schiff base between one of the reactants and a lysine in the active 


\section{Organic and Medicinal Chemistry International Journal}

site of the enzyme. For example, when plants convert carbon in the form of $\mathrm{CO}_{2}$ into carbohydrate, one of the early reactions that take place is the condensation of the four-carbon sugar erythrose-4-phosphate (E4P) with dihydroxyacetone phosphate (DHAP) to form the seven-carbon sugar sedoheptulose-1, 7-bisphosphate (Figure 8).

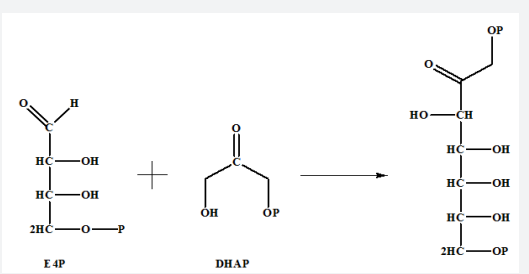

Figure 8: Condensation of E4P with DHAP to form sedoheptulose-1, 7-bisphosphate.

The DHAP substrate binds to the enzyme first, and forms a Schiff base with a specific active site lysine residue (Figure 9). When we study this reaction in its entirety and see how the formation of the Schiff base is a critical part of the enzyme's catalytic strategy. The e-amino group of an active site lysine residue reacts with the carbonyl $\mathrm{C}$ of sedoheptulose-7-phosphate to form a protonated Schiff base intermediate [8] (Figure 10).

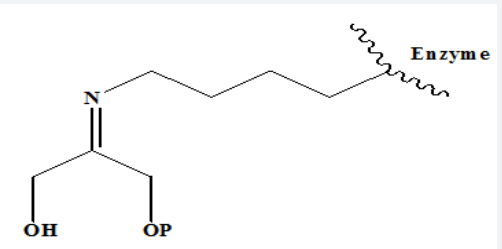

Figure 9: DHAP substrate binds to the Enzyme.

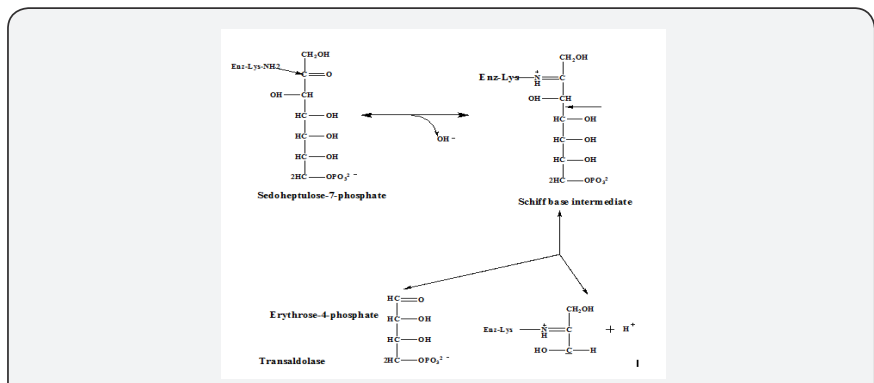

Figure 10: Formation of Protonated intermediate Schiff base.

\section{Literature Review on Schiff Base and Hydrazones}

\section{Introduction of Schiff Base}

Schiff base metal complexes have been studied extensively because of their attractive chemical and physical properties and their wide range of applications in numerous scientific areas. These types of complexes have been vigorously explored in recent years and such studies have been the subject of many papers and reviews. Many of them are centered on the catalytic activity of Schiff base complexes in a large number of homogeneous and heterogeneous reactions.

\section{Schiff base ligands}

The presence of a lone pair of electrons in a sp2 hybridized orbital of the nitrogen atom of the azomethines group is of considerable chemical importance and impart excellent chelating ability especially when used in combination with one or more donor atoms close to the azomethines group. Examples of a few compounds are given in (Figure 1). This chelating ability of the Schiff bases combined with the ease of preparation and flexibility in varying the chemical environment about the $\mathrm{C}=\mathrm{N}$ group makes it an interesting ligand in coordination chemistry (Figure 11). When an aldehyde is a salicylaldehyde derivative and the amine is a diamine derivative, the condensation produces interesting $\mathrm{N}_{2} \mathrm{O}_{2}$ Schiff base compounds (Figure 12). The so called salen ligands are very much like porphyries and, unlike the latter, can be easily prepared.

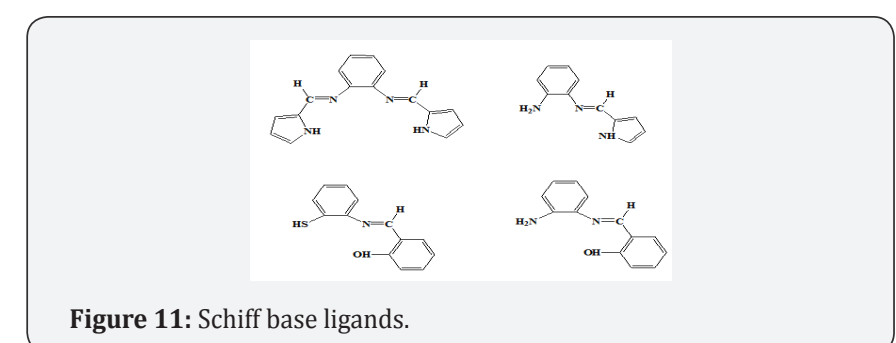

Figure 11: Schiff base ligands.

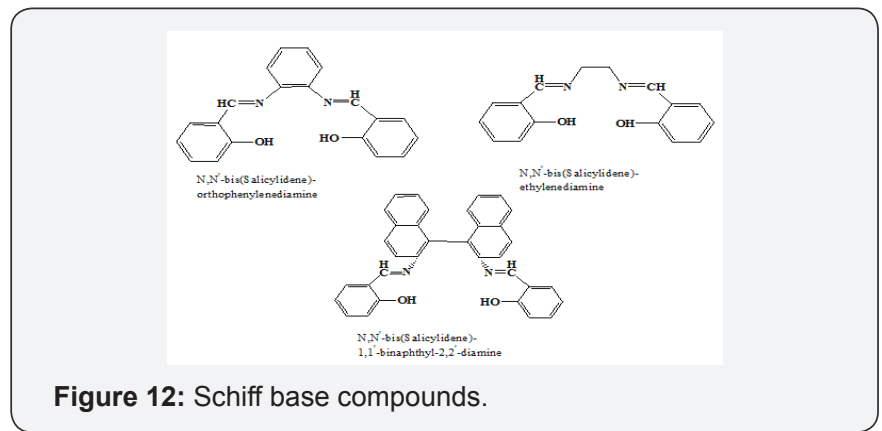

\section{Schiff base transition metal complex and its activity}

Cozzi et al. [9], (2004) in his review has outlined five synthetic routes that are commonly employed for the preparation of Schiff base metal complexes and these are depicted in (Figure13). Route 1 involves the use of metal alkoxides (M (OR) n). Alkoxides of early transition metals ( $\mathrm{M}=\mathrm{Ti}, \mathrm{Zr}$ ), are commercially available and easy to handle. The use of other alkoxides derivatives is not easy, particularly in the case of highly moisture-sensitive derivatives of lanthanides. Metal amides $\mathrm{M}(\mathrm{NMe} 2) 4(\mathrm{M}=\mathrm{Ti}$, $\mathrm{Zr}$ ) are also employed as the precursors in the preparation of Schiff base metal complexes (Route 2). The reaction occurs via the elimination of the acidic phenolic proton of the Schiff bases through the formation of volatile NHMe2. Other synthetic routes include treatment of metal alkyl complexes with Schiff bases (Route 3) or treatment of the Schiff base with the corresponding metal acetate under reflux conditions (Route 4). The synthetic scheme presented in route 5 which is quite effective in obtaining salen-type metal complexes consists of a two-step reaction 


\section{Organic and Medicinal Chemistry International Journal}

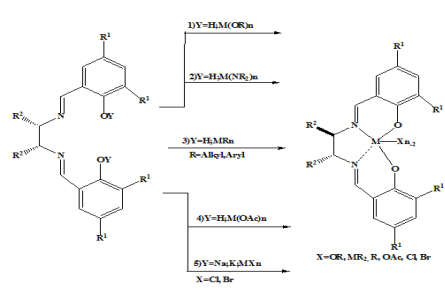

Figure 13: Schiff base transition metal complexes.

involving the deprotonation of the Schiff bases followed by reaction with metal halides.

Dong-Hoon Won et al. [10], (2006) have studied the synthesis and crystal structure of the following Schiff base (Figure 14) macro cycles bearing thiophene. Ibrahim, Sharif et al. [11], (2007) have reported the synthesis, characterization of Schiff base (Figure 15) which can be used as fluorometric analytical reagents. Gudasi et al. [12], (2006) have reported the synthesis, characterization and biological activity of dioxouranium (II) and thorium (IV) complexe of Schiff base derived from 2-amino pyridine and acetophenones. (Figure 16), More et al. [13], (2006) have reported the synthesis of the following Schiff base. These authors have studied the proton ligand stability constant of the Schiff base and the formation of the constant of their transition metal complexes (Figure 17).

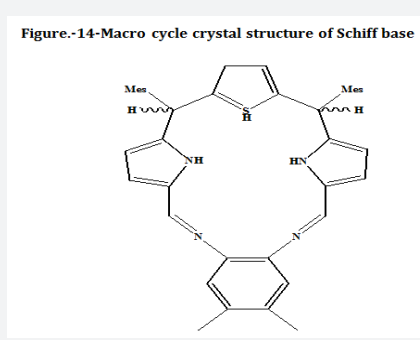

Figure 14: Macro cycle crystal structure of Schiff base.

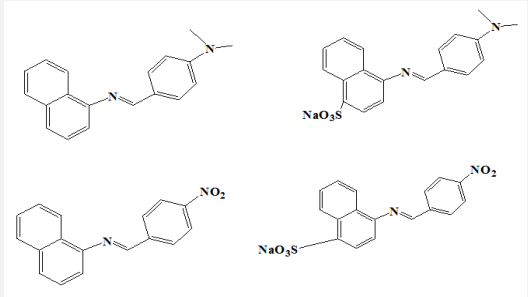

Figure 15: Schiff base derivatives.

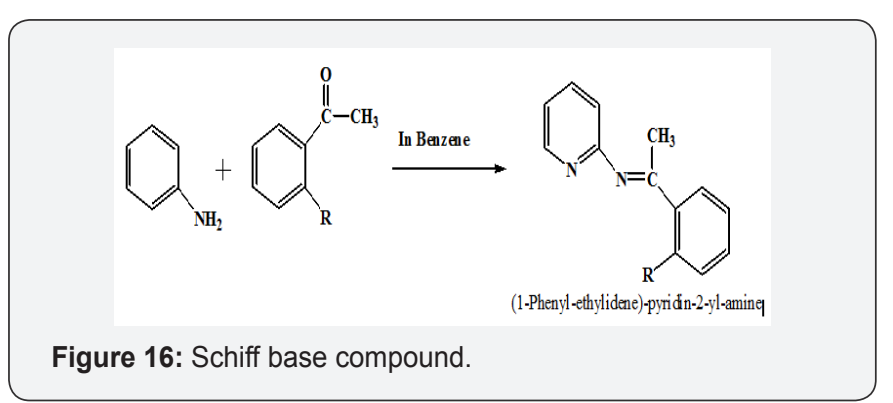

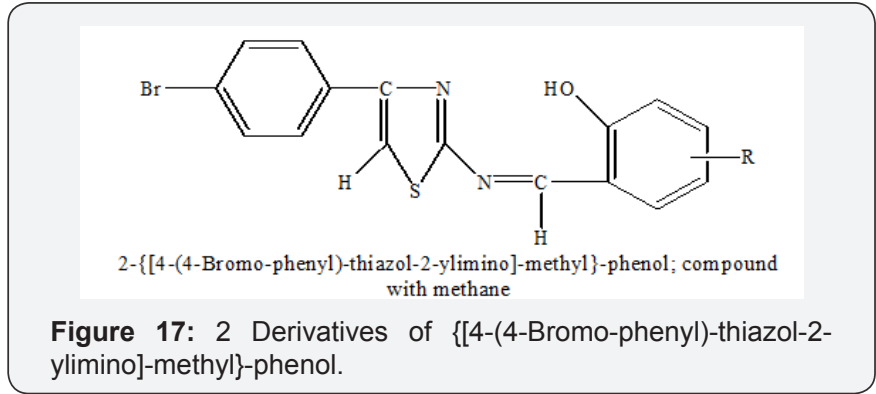

\section{Schiff base electrochemical properties}

Kulkarni et al. [14], (2009) have synthesized Schiff base and studied the electrochemical properties of their complexes. (Figure 18), N Raman et al. [15], (2003) have synthesis, characterization and electrochemical behavior of $\mathrm{Cu}(\mathrm{II}), \mathrm{Co}(\mathrm{II})$, $\mathrm{Ni}(\mathrm{II})$ and $\mathrm{Zn}(\mathrm{II})$ complexes derived from acetyl acetone and $\mathrm{p}$-anisidine were reported. These authors have observed that the complexes synthesized by them show fairly good antimicrobial activity. (Figure 19), Farias and Bastos et al. [16], (2009) have studied the electro chemical behavior of copper (II) complexes of the Schiff ,base N, N-ethylene bis (salicylidimine) in aqueous phosphate ( $\mathrm{pH} 7$ ) by photographic and voltammetric techniques at a mercury electrode. It is a symmetrical molecule and exhibits chiral properties (Figure 20).

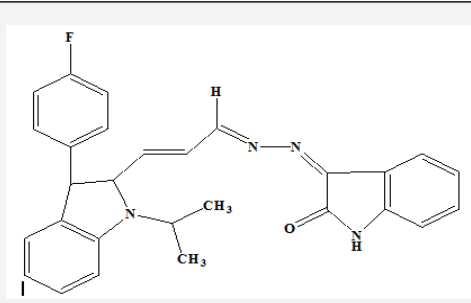

Figure 18: 3-(3-[3-(4-Fluoro-phenyl)-1-isopropyl-2,3-dihydro$1 \mathrm{H}$-indol-2-yl]-allylidene\}-hydrazono)-1,3-dihydro-indol-2-one.

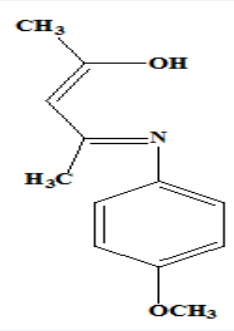

Figure 19: 4-(4-Methoxy-phenylimino)-pent-2-en-2-ol.

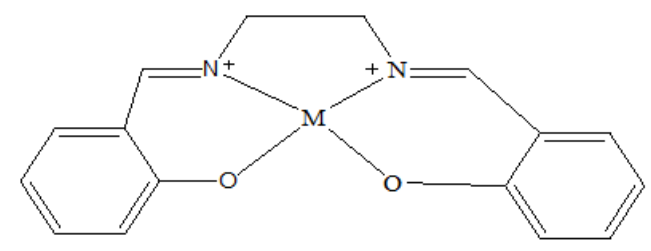

Figure 20: Schiff base compound. 


\section{Organic and Medicinal Chemistry International Journal}

\section{Linear and non-linear optical properties}

Iran Sheikhshoaie and Saeedina et al. [17], (2010) have reported the synthesis, characterization and nonlinear optical properties of the following four Schiff bases (Figure 21). Gao and Zheng et al. [18], (2002) have reported the synthesis, of optically active Schiff base ligand derived from the condensation of 2-hydroxyacetophenone and 1,2-diaminocyclohexane (Figure 22).
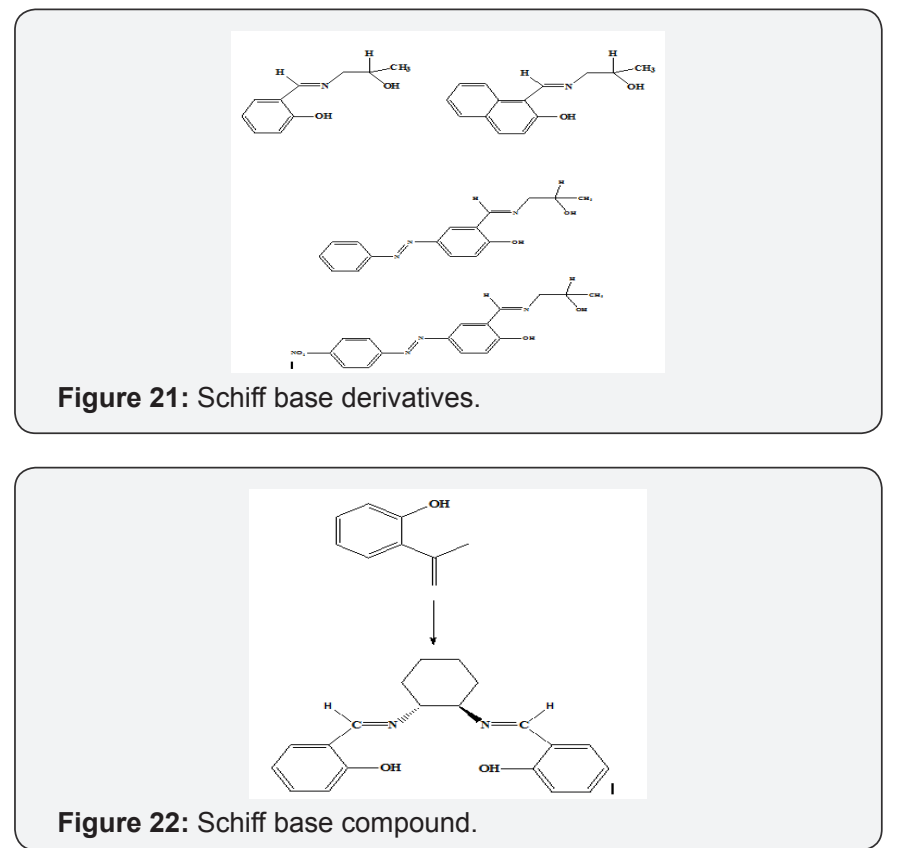

\section{Applications of Schiff base transition metal complexes}

I. Schiff base transition metal complexes in catalysis: A discussion on the catalytic activity of Schiff base metal complexes in various reactions are outlined in this section.

II. Oxidation reactions: Uchida and Katsuki et al. [19], (2001) reported the activity of cationic cobalt (III) salen complexes in Baeyer-Villiger oxidation of 3-phenyl cyclobutanone with $\mathrm{H}_{2} \mathrm{O}_{2}$ or urea-hydrogen peroxide adduct. The analogous [ $\operatorname{Zr}($ salen)] catalysts are also active in BaeyerVilliger oxidation of cyclobutanone derivatives to produce lactones in 75-99\% yields and 69-78\%in the presence of $\mathrm{H} 2 \mathrm{O} 2$ as an oxidant [20]. Reddy and Thornon et al. [21], (1992) reported that complexes (1) and (2) in (Figure 23) catalyze the oxidation of a range of ketone silylenol ethers to give $\alpha$-hydroxyketones using iodosylbenzene as oxidant in acetonitrile at room temperature. Later, Waldemar et al. [22] (1998) showed that (1) also catalyzes the asymmetric oxidation of silyl ketene acetals in high enantioselectivity. Nakajima et al. [23], 1986 studied the application of chiral Schiff base complexes in enantioselectivity sulfide oxidations. Using tetra dentate Schiff base-oxovanadium (IV) complex, (Figure 24), as catalyst, they could achieve an enantioselectivity of $42 \%$ in the oxidation of methylphenyl sulfide to the corresponding sulfoxide.

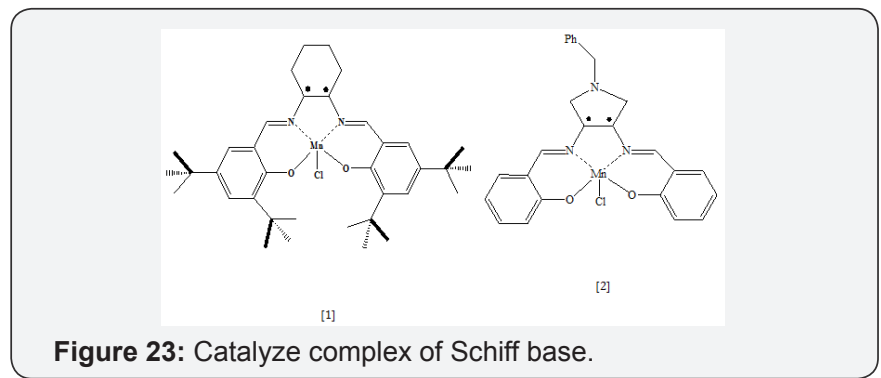

Figure 23: Catalyze complex of Schiff base.

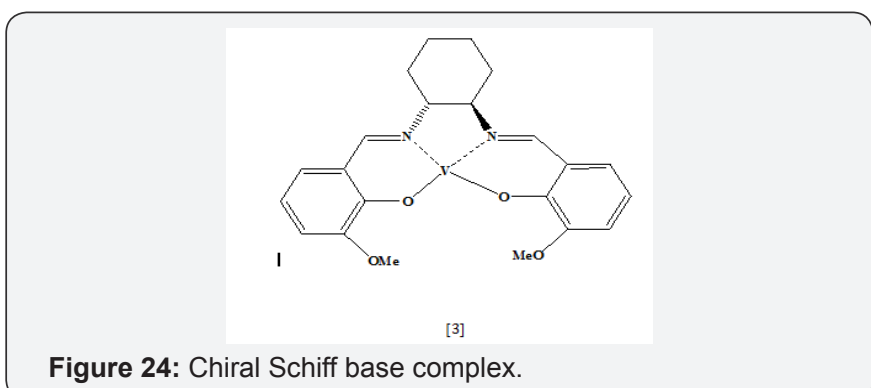

III. Epoxidation reactions: Katsuki et al. [24-26] introduced the second-generation Mn-(salen) catalysts have surpassed Jacobsen's catalyst in terms of selectivity and activity, but they are not as synthetically accessible, and this has limited their application. (Figure 25), Zhao et al. [27], (1996)The manganese Schiff base chelate, synthesized by exhibit moderate asymmetric induction (31-74\%) in the epoxidation of decahydronaphthalene with higher turnover number 2728, (Figure 26).

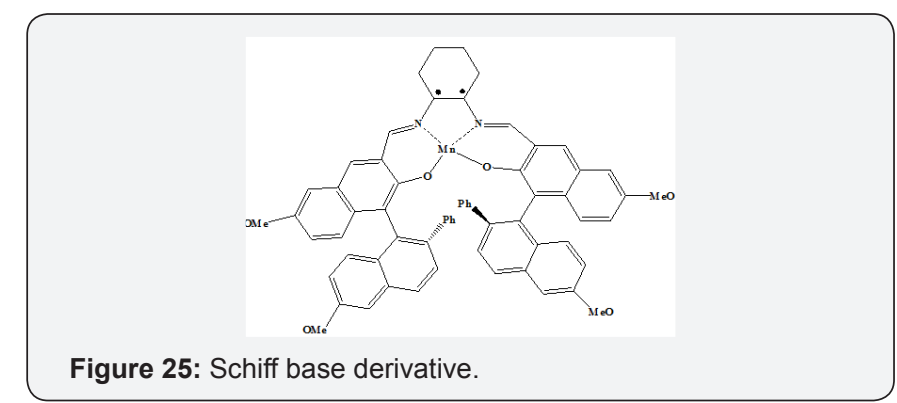

Figure 25: Schiff base derivative.

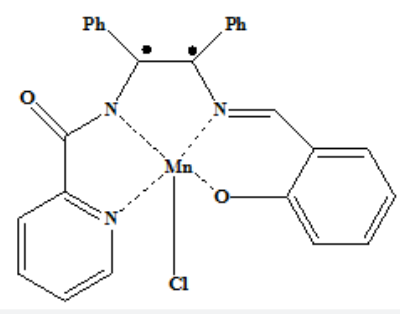

Figure 26: Magnese Schiff base Chelate.

IV. Polymerization reactions: Aluminum complexes of a series of tridentate Schiff base ligands were found to catalyze the polymerization of ethylene [28] (Figure 27). A number of pyridyl bis(imide) complexes and phenoxy imines complexes are used as catalysts in the polymerization of 


\section{Organic and Medicinal Chemistry International Journal}

ethylene [29-32]. Pyridine bis(imines) complexes of iron(III) and cobalt(II) show significant activity in the polymerization of ethylene and copolymerization of ethylene with 1-hexene [33].

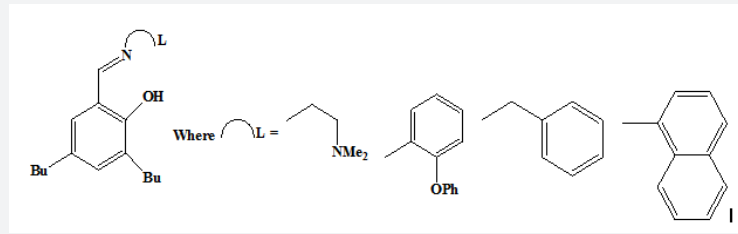

Figure 27: Schiff base derivatives.

V. Hydrogenation reactions: Venkatachalam et al. [34], (2006) also reported the transfer hydrogenation of imines to amines mediated by ruthenium (III) bis-bidentate Schiff base complexes. The catalytic activity in the transfer hydrogenation of aliphatic and aromatic ketones in the presence of isopropanol and $\mathrm{KOH}$ has been investigated with ruthenium(III) Schiff base complexes of general formula [RuX(EPh3)(LL')] where $\mathrm{X}=\mathrm{Cl}$ or $\mathrm{Br}, \mathrm{E}=\mathrm{P}$ or As and LL' = [ONNO] donor of the heterocyclic Schiff base ligands [35] (Figure 28).

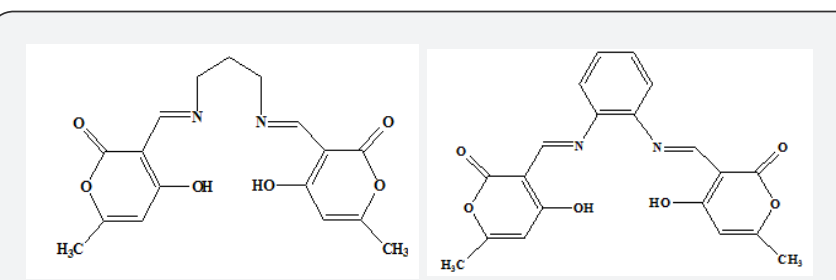

Figure 28: Bis-bidentate Schiff base complexes.

\section{Biological Activity of Schiff base and Hydrazones}

\section{Analgesic, Anti-inflammatory activity}

Sondhi et al. [36], (2006) reported the synthesis of $\mathrm{N}$-(acridin-9-yl)-4 (benzo[d]imidazol/oxazol-2-yl) benzamides Schiff bases which exhibit analgesic and anti-inflammatory activity. Chinnasamy et al. [37], (2010) reported the synthesis of series of novel Schiff bases of Isatin. 3-(4-(4-Hydroxy-3methoxylbenzylideneamino) phenyl amino) indoline-2-one exhibited better analgesic activity when compared to standard pentazocine. Bhandari et al. [38], (2008) Schiff bases derived from 2-[(2,6-dichloroanilino) phenyl] acetic acid (Diclofenac acid) XVI was synthesized and studied for their anti-inflammatory, analgesic and ulcerogenic activities (Figure 29-32).

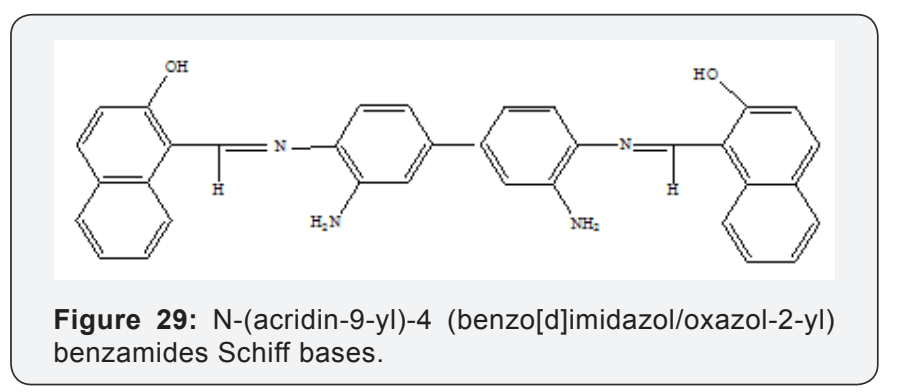

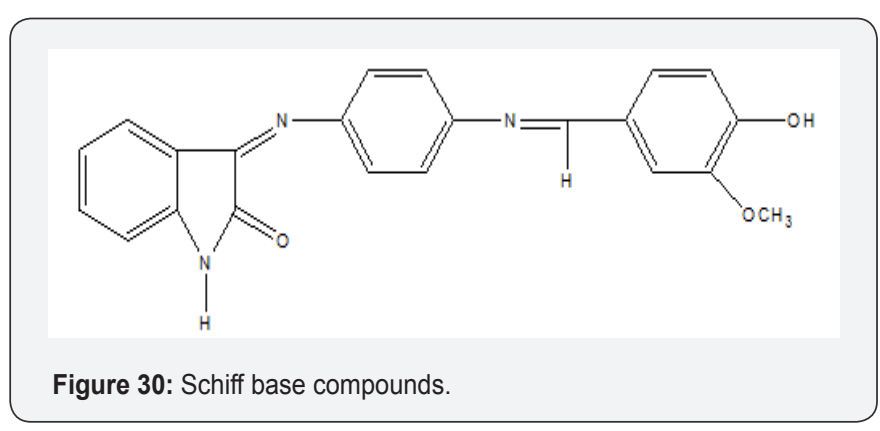
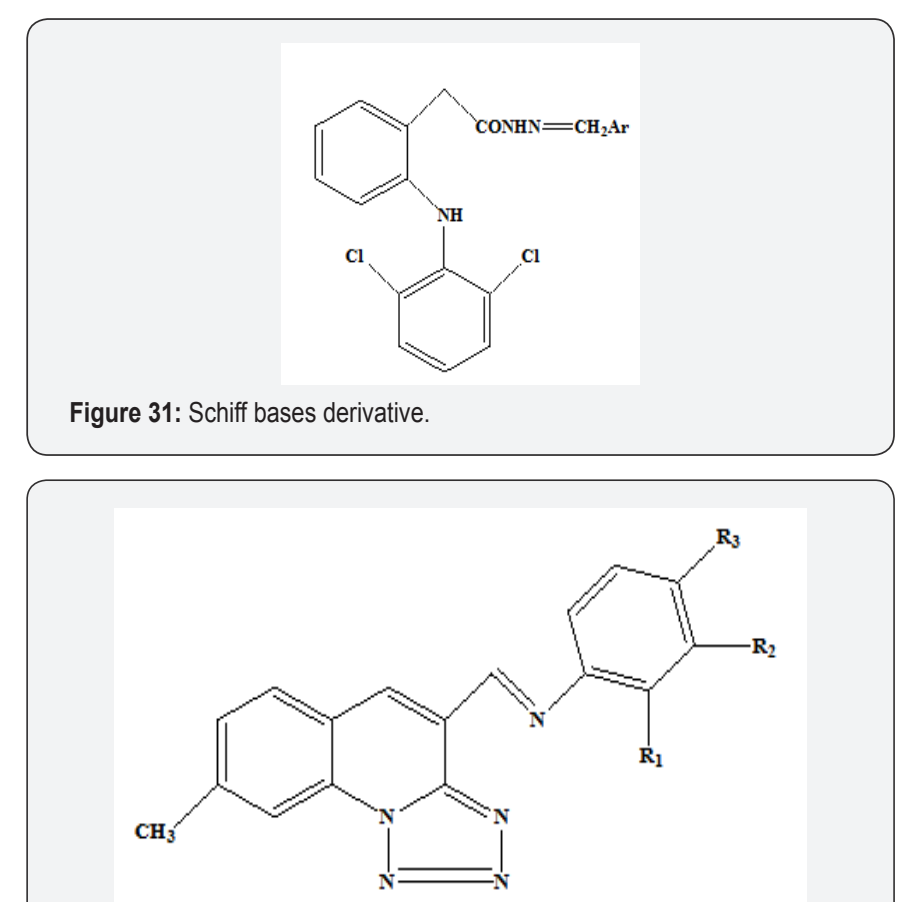

Figure 32: Schiff base of 8-methyl-tetrazolo [1,5-a] Quinoline derivatives.

Bawa and Kumar et al. [39], (2009) have synthesized Schiff base of 8-methyl-tetrazolo [1,5-a] Quinoline and evaluated their anti-inflammatory and antimicrobial activities. Lima et al. [40], (2000) have synthesized [(4-dimethylamino benzylidene-3-(3, 4-methylenedioxyphenyl) propionylhydrazine] was more potent than dipyrone and indomethacin are used as standard antiinflammatory / antinociceptive drugs. Panneerselvam et al. [41], (2009) have been synthesized 4-(2-aminophenyl)-morph lines Schiff base and studied for their analgesic, anti-inflammatory, antibacterial and antifungal activities (Figures $33 \& 34$ ).

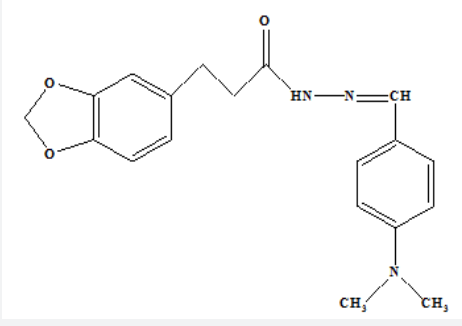

Figure 33: [(4-dimethyl amino benzylidene-3- (3,4 methylenedioxyphenyl) propionylhydrazine]. 


\section{Organic and Medicinal Chemistry International Journal}

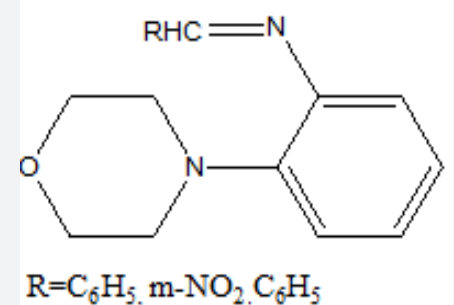

Figure 34: 4-(2-aminophenyl)-morph lines Schiff base.

\section{Antimicrobial activity}

$\mathrm{N}$ Raman et al. [42], (2007) synthesized a series of transition metal complex of $\mathrm{Cu}(\mathrm{II}), \mathrm{Ni}(\mathrm{II}), \mathrm{Co}(\mathrm{II}), \mathrm{Mn}(\mathrm{II}), \mathrm{Zn}(\mathrm{II})$, VO(IV), Hg(II) and Cd(II) from the Schiff base (L) derived from 4-aminoantipyrine, 3-hydroxy-4-nitrobenaldehyde and o-phenylenediamine which have DNA cleavage activity and antimicrobial activity against Salmonella typhi, Staphylococcus aureus, E. coli, B. subtilis by the well diffusion method. G. Nageswara Reddy et al. [43], (2011) synthesized and investigated of new Schiff base and its solid metal complexes derived from p-Toluichydrazide and 2-hydroxy-3-methoxy benzaldehyde (OVPTH) by using modified Sand Mayer's method. The compound has antimicrobial activity against Salmonella typhi, Enterococcus faecailis and, E. coli (Figures 35-37).

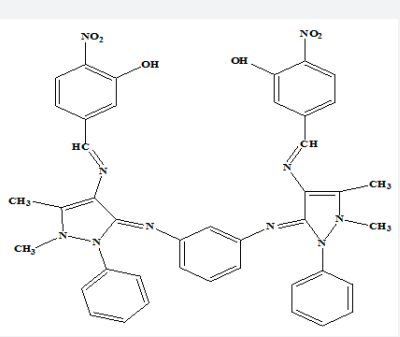

Figure 35: Transition metal complex from the Schiff base.

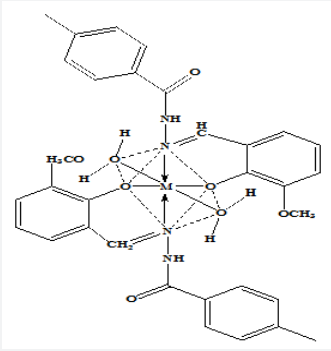

Figure 36: Schiff base metal complexes.

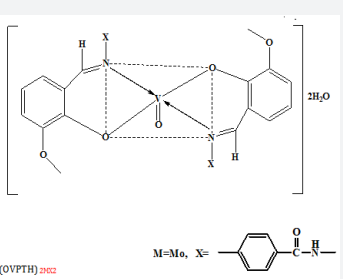

Figure 37: Schiff base metal complexes.
Muhammad et al. [44], (2011) a series of binuclear Schiff base derived from 1,5-diaminonaphthalene, glyxol/ biacetyl and 2-aminophenol. The Schiff bases their complexes have been screened for their in vitro (Staphylococcus aureus, E. coli, B. subtilis and Klebsilla pneumonia) activity by paper disc method, it result confirms the binuclear complexes are more potent than free ligands. (Figure 38), Muhammad Aqeel Ashraf et al. [44], (2012) synthesized three new series of biologically active amino substituted Schiff base with general formula $\mathrm{R}_{1} \mathrm{~N}=\mathrm{CHR}_{2}$.

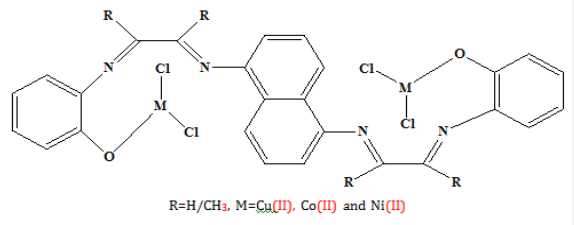

Figure 38: Binuclear Schiff base derivative.

Here, $\mathrm{R}_{1}=2$-amino-benzthiazole, 4-amino-salicylic acid and 4-aminophenol, $\mathrm{R}_{2}=4$-chloro-benzaldehyde, 2 - chlorobenzaldehyde, salicylaldehyde, vanillin and benzaldehyde were synthesized by the reaction of three different amino substituted compounds and substituted aldehyde in ethanol. The free ligand and their metal complexes have been screened for their in vitro biological activity against bacteria, fungi and yeast (Figure 39).

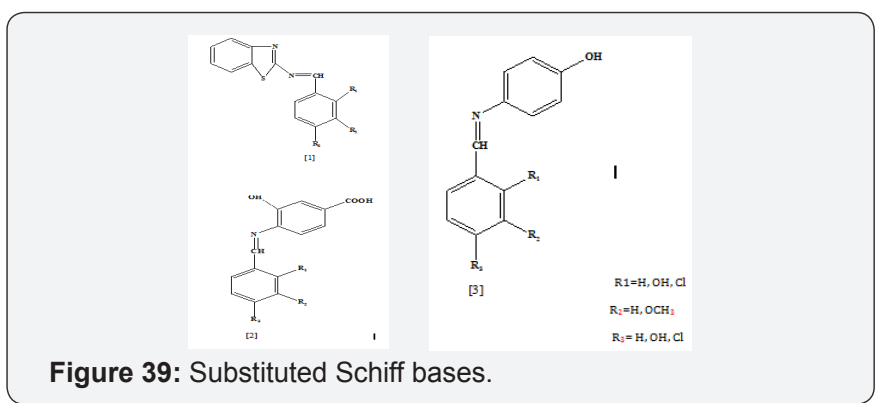

Kucukguzel et al. [45], (2002) have synthesized'-(4methoxybenzamido) benzoyl] -2-[(5-nitro-2-furyl) methylene] hydrazine inhibited the growth of several bacteria and fungi. Mamolo M G et al. [46], (2003) have prepared some 5-Bromoimidazo [1, 2-a] pyridine-2-carboxylic acid benzylidene hydrazide and screened their antimicrobial activity. Sari et al. [47], (2003) have reported the synthesis and antibacterial activities of some new amino acid Schiff base. Daniel Thangadurai et al. [48], (2003) have reported the synthesis and antibacterial activities of chiral Schiff base Ruthenium (III) complex. The catalytic and antibacterial activities of these compounds have also been reported (Figures 40-43).

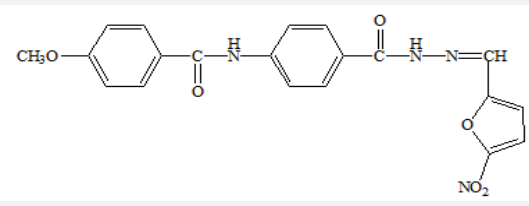

Figure 40: (4-methoxybenzamido) benzoyl] -2-[(5-nitro-2-furyl) methylene] hydrazine 


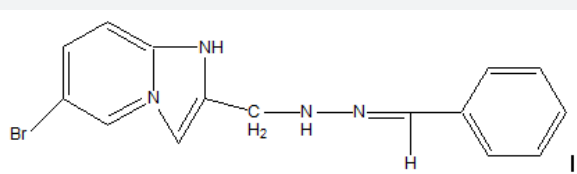

Figure 41: 5-Bromoimidazo [1, 2-a] pyridine-2-carboxylic acid benzylidene hydrazide.

$$
\text { (c) }
$$

Figure 42: Schiff base derivatives.

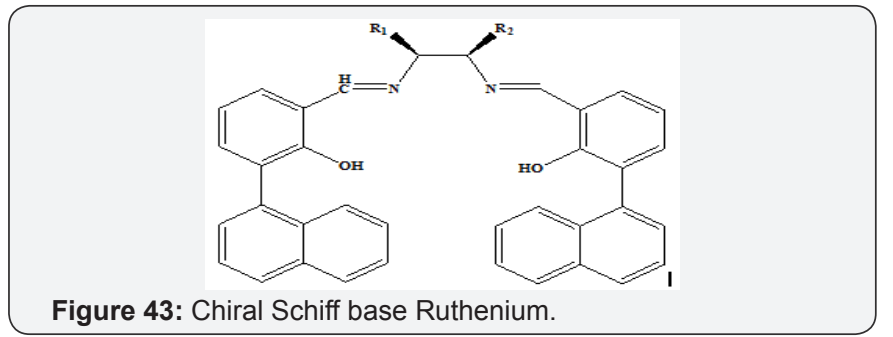

Baluja et al. [49], (2006) have studied the antibacterial activities of the following Schiff base. Spinu et al. [50], (2007) have reported the synthesis and antibacterial activity of Schiff base by the condensation of 2-thiophenecaroxaldehyde with 2-aminopyridine.N-(2-thienylmethylidene)-2-aminopyridine (TNAPY). Nair et al. [51], (2006) have reported the synthesis and antibacterial activities of some Schiff base complexes.The Schiff bases showed greater activity than their metal complexes. Morad et al. [52], (2007) have reported the synthesis, physical characterization and antibacterial activities of Ni(II) Schiff base complexes (scheme) (Figures 44-47).

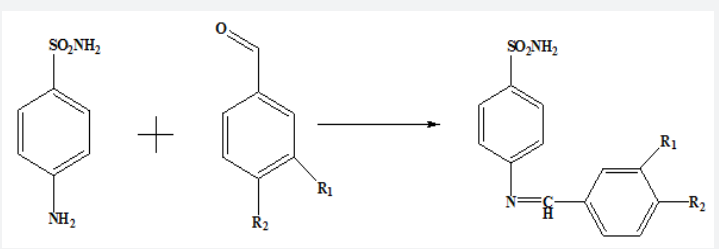

Figure 44: Schiff base derivatives.

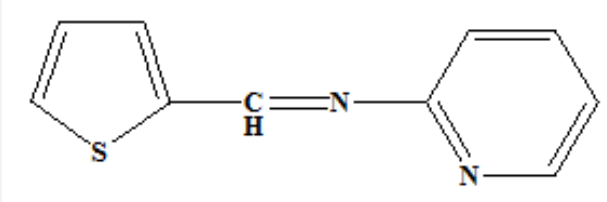

Figure 45: Schiff base.

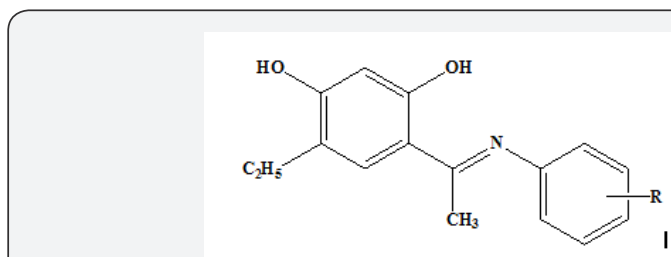

Figure 46: Schiff base compound.

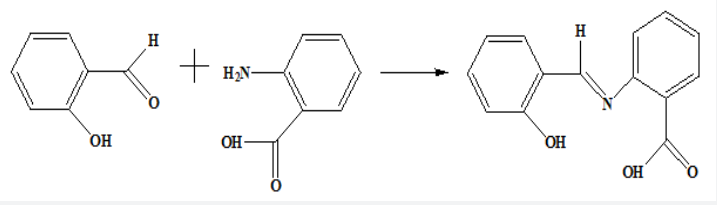

Figure 47: Schiff base complexes.

Faizul et al. [53], (2007) have reported the synthesis of Schiff bases of naptha [1,2-d]thiazol-2-amine and metal complexes of 2-(2,-hydroxy)benzylidene amino napthathiazole as a potential antimicrobial agent. Raman et al. [54], (2007) have reported the synthesis of the following Schiff base ligand. These authors have studied the DNA cleavage and antimicrobial activity of the Schiff base transition metal complexes. Elzahany et al. [55], (2008) have synthesized of the following transition metal complexes with Schiff bases derived from 2-formylindole, salicylaldehyde, and $\mathrm{N}$-amino Rhoda nine. The free ligand and their metal complexes where also screened for antimicrobial activities against B. cerens, E. coli, P. aeruginosa, S. aureus and Candida albicans (Figure 47$50)$.

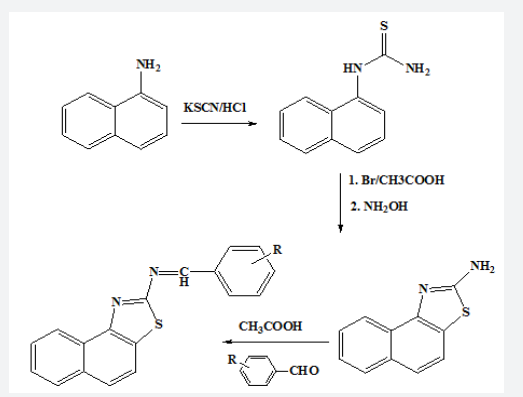

Figure 48: Schiff bases of naptha [1,2-d]thiazol-2-amine.

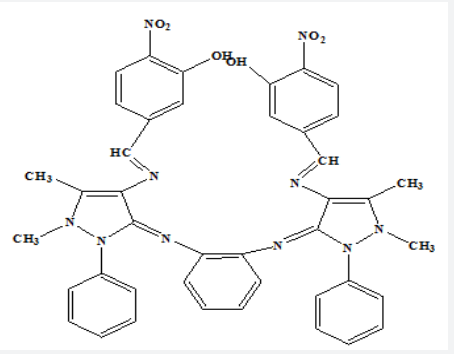

Figure 49: Schiff base ligand. 


\section{Organic and Medicinal Chemistry International Journal}<smiles>CC=Cc1c[nH]c2ccccc12</smiles><smiles>CC=Cc1ccccc1O</smiles><smiles>O=C1CCCCC1=O</smiles><smiles>CN1C(=O)CSC1=O</smiles>

Figure 50: Transition metal complexes of Schiff bases.

Desai RM et al. [56], (1999) have synthesized some new 1,3,4-oxadiazoles, sulphonamides, 5-imidazolinones, azomethanes, 4-thiazolidinones, 2-azetidinones, formazans, Schiff base and terazolium chlorides which have shown antimicrobial activity against E. coli, P. fluorescence, B. mega, B. subtilis. Compounds also exhibited the antifungal activity against A. awamori at $50 \mathrm{mg} / \mathrm{ml}$ concentration. The formazans (a-g) have been prepared by coupling reaction of solution sulphonamides with azomethines (5a-en) in pyridine at temperature $0-5^{\circ} \mathrm{C}$ (Figure 51).

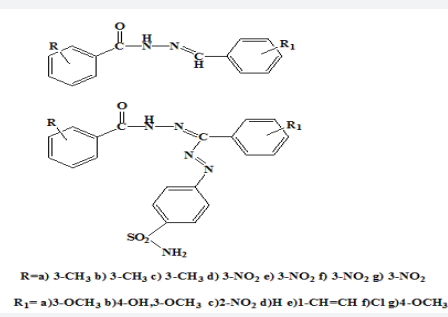

Figure 51: some new Schiff base compounds.

Desai KG et al. [57], (2005) have synthesized active Schiff bases using microwave method and their derivatives Formazans which have shown antimicrobial activity against B. substilis, E. coli and S. aureus. The synthesized compounds also exhibited the antifungal activity against $\mathrm{C}$ albicans and A. Niger by filter paper disc technique. Different formazans were synthesized by condensation of p- nitrobenzoyl hydride with substituted aromatic aldehydes under microwave irradiation and also by a conventional method to produce Schiff bases (3a-j).

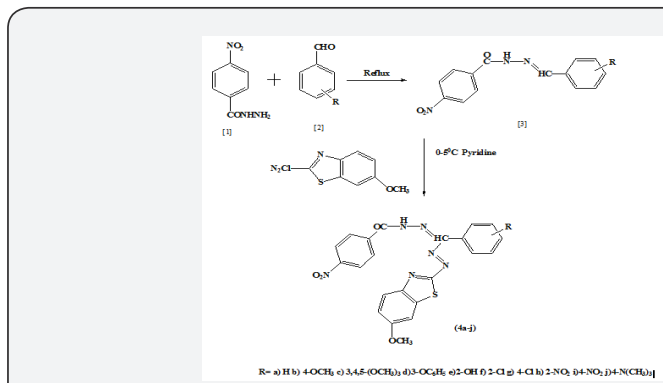

Figure 52: Schiff bases derivatives.

These Schiff bases on condensation with a diazonium salt of 6-methoxy-2-aminobenzothiazole give formazans (4a-j). (Figure 52), Pandey VK and Negi HS et al. [58], (1999) have synthesized
1 ' - (2' - aryl - 4 - oxo(3H) qunazolyl) -3- aryl -5- phenyl formazans and the compounds have shown antiviral activity against Vaccinia virus in chick embryo fibroblast. 1' - (2 ' - aryl 4 - oxo (3H) qunazolyl) -3- aryl -5- phenyl formazans have been prepared by reaction of 2-aryl- 3 - (diazo chloro) - qunazolyl $(3 \mathrm{H})$ - 1- one with stirring to aryl hydrozone in pyridine maintaining the temperature between 5 and $10^{\circ} \mathrm{C}$ (Figure 53).

WadherSJetal. [59],(2009) havereported AseriesofSchiffbase and 2-azetidinonesof 4,4'-diaminodiphenylsulphonehavebeen synthesized. 4,4'-diaminodiphenylsulphone was condensed with various aromatic or heterocyclic aldehyde in ethanol in the presence of concentrated sulphuricacidas a catalyst to yield the Schiff base. All these compounds were evaluated for their in vitro activity against several microbes. Some compounds exhibited potent antibacterial activity with the reference standard ciprofloxacin and fluconazol (Figure 54).

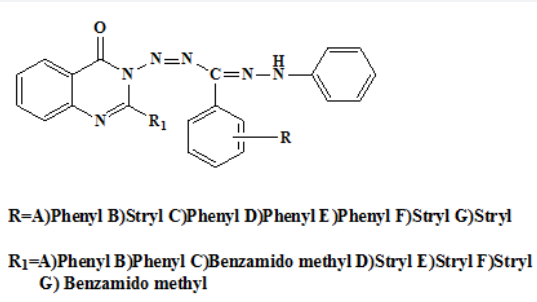

Figure 53: 1 ' - (2 ' - aryl - 4 - oxo (3H) qunazolyl) -3- aryl -5- phenyl formazans.<smiles>[R]C=Nc1ccc(S(=O)c2ccc(/N=C\[R])cc2)cc1</smiles>

Figure 54: Siphoned derivative Schiff base.

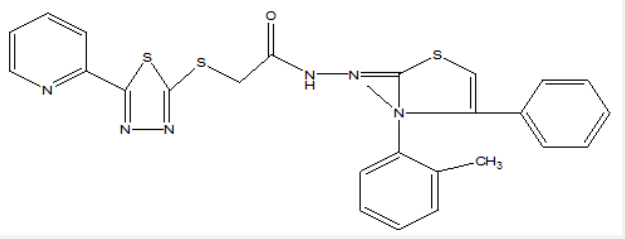

Figure 55: [5-(pyridine-2-yl)-1,3,4-thidiazole-2-yl]acetic acid (3,4-diaryl-3H-thiazole-2 ylidene)hydrazide.

\section{Anti-tubercular activity}

Mamolo et al. [60], (2003) have synthesized [5-(pyridine-2yl)-1, 3, 4-thidiazole-2-yl] acetic acid (3,4-diaryl-3H-thiazole-2ylidene)hydrazide and tested for their invitro antimycobacterial activity. Sinha et al. [61], (2005) have synthesized-arylidene-[2-oxo-2-(4-arylpiperazin- yl) ethyl] hydrazide derivatives containing is nicotinic acid hydrazide hydrazones and evaluated 


\section{Organic and Medicinal Chemistry International Journal}

their antimycobacterial activity. Sriram et al. [62], (2006) various diclofenac acid hydrazones were synthesized and evaluated for their in vitro and in vivo antimycobacterial activities. Hearn and Cynamon et al. [63], (2004) have reported the synthesis of Schiff base the antitubercular activity of Schiff base (Figures 54-58).

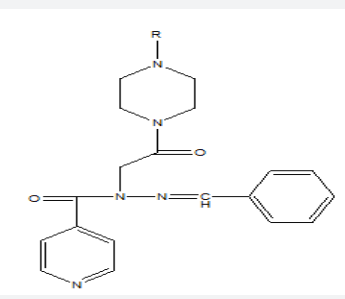

Figure 56: arylidene-_-[2-oxo-2-(4-arylpiperazin-yl) ethyl] hydrazide derivatives.

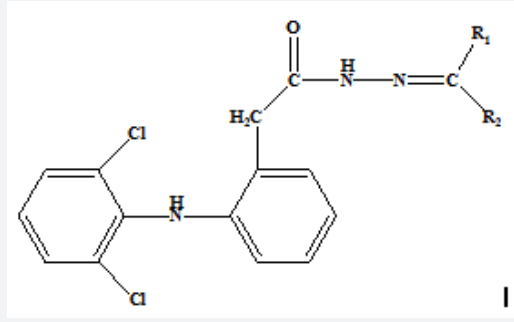

Figure 57: Diclofenac acid hydrazones.

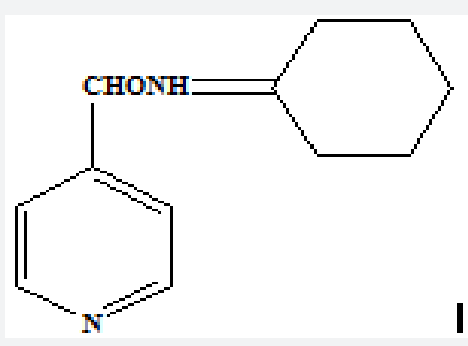

Figure 58: C-Pyridin-4-yl-methyleneamine; compound with cyclohexanone.

\section{Anticancer activity/antitumor}

Demirbas et al. [64], (2004) have synthesized new hydrazide-hydrazones containing 5-oxo-[1,2,4]triazole ring and studied their antitumor activity in breast cancer. Terzioglu and Gursoy et al. [65], (2003) have synthesized some novel 2,6-dimethyl- substituted-phenylmethyleneimidazo[2,1-b] $[1,3,4]$ thiadiazole-5-carbohydrazides showed the most favorable cytotoxicity. Kamel et al. [66], (2010) a series of sulfapyridinepolyhydroxyalkylidene (or arylidene)-imino derivatives have been prepared and reported for antitumor activity (Figures 5861).

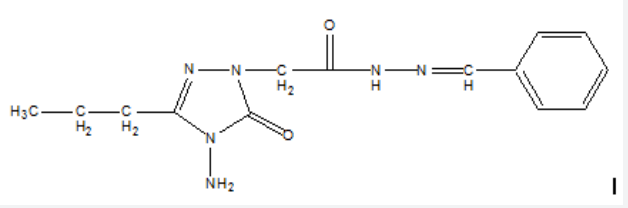

Figure 59: Hydrazide -hydrazones containing 5-oxo$[1,2,4]$ triazole derivative.
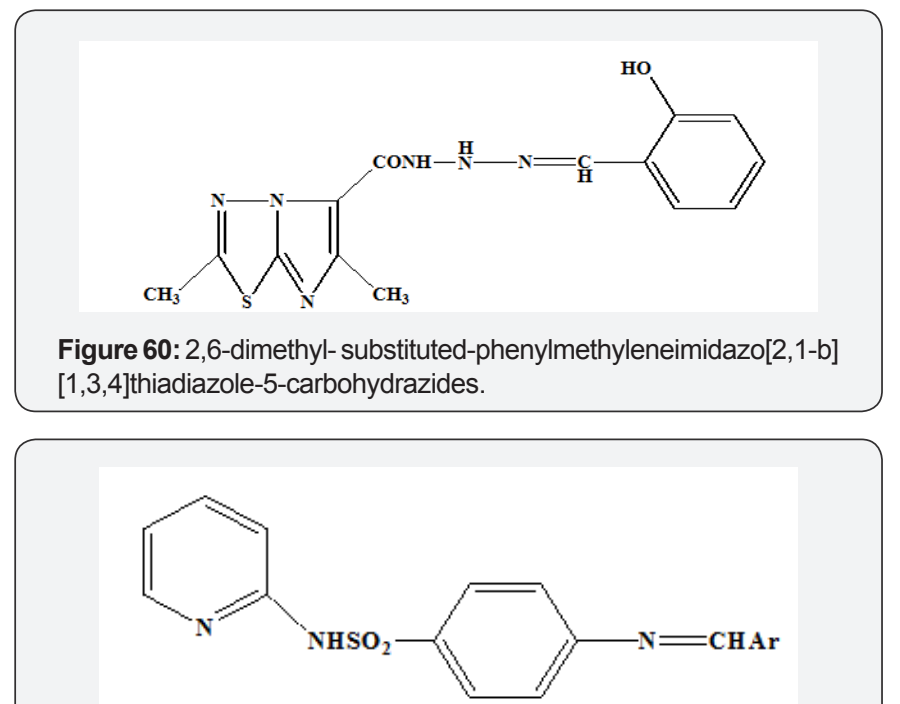

Figure 61: Sulfapyridine-polyhydroxyalkylidene (or arylidene)-imino derivatives.

Gursoy and Guzeldemirci-Ulusoy et al. [67], (2007) have synthesized 6-amino-4-aryl-2-oxo-1-(1-pyrid-3-yl- or 4-ylethylidene-amino)-1,2-dihydro pyridine-3,5-dicarbo-nitrile and studied their antitumor activity. Shabani et al. [68], (2010) have reported the synthesis, characterization and anti-tumor activity of Iron Schiff base complexes (Figure 61-63).

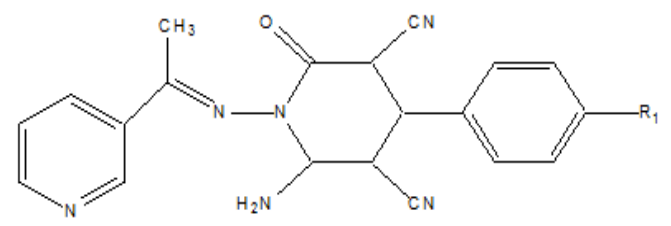

Figure 62: 6-amino-4-aryl-2-oxo-1- (1-pyrid-3-yl- or 4-yl-ethylideneamino)-1,2-dihydro pyridine-3,5-dicarbo-nitrile derivative.

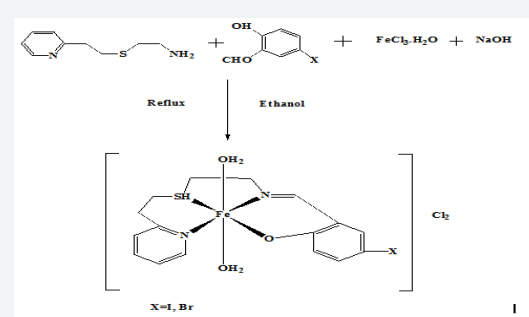

Figure 63: Iron Schiff base complexes.

\section{Anticonvulsant}

Ragavendran et al. [69], (2007) synthesized 4-Aminobutyric acid (GABA) is the principal inhibitory neurotransmitter in the mammalian brain. GABA hydrazones were synthesized and evaluated for their anticonvulsant properties in different animal models Dimmock et al. [70], (2000) have synthesized acetyl hydrazones provided good protection against convulsions while the oxamoylhydrazones were significantly less active. 


\section{Organic and Medicinal Chemistry International Journal}

Archana, Srivastava et al. [71], (2003) have synthesized new erindolylthiadiazoles and their thiazolidionones and formazans which have shown potential anti convulsing activity (Figures 64 \&65).

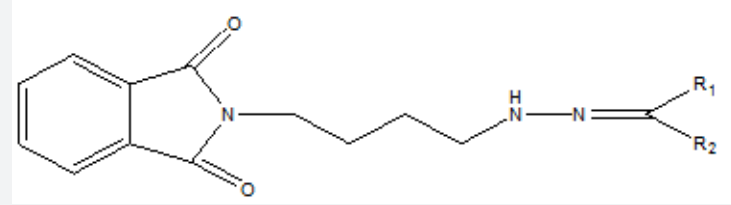

Figure 64: GABA hydrazones.<smiles>[Y9]C(=NNC(=O)C(N)=O)c1cc([R3])cc([R1])c1</smiles>

Figure 65: Acetyl hydrazones.

A series of 2- (substituted aryldennyl imino) -5- (3 indolomethylene) - 1,3,4 - thiadiazole have been synthesized via condensation of2- amino -5- (- indolomethylene) - 1,3,4 thiadiazole (3) with various aromaticaldehydes. Cyclo addition of thiglycolic acid to (4-8) yielded 3-[5- (3"Indole

methylene) - 1',3 ', 4' -thiadiazole - 2 'yl] -2- substituted aryl -4- thiazolidionones and with diazonium salt solution of 4-8 gave 1- [ 5 '-(3 ' Indole methylene) - 2 ' - imino- 1',3 ', 4' -thiadiazole - 2 'yl] -1,2- substituted aryl ] formazans (Figure 66).

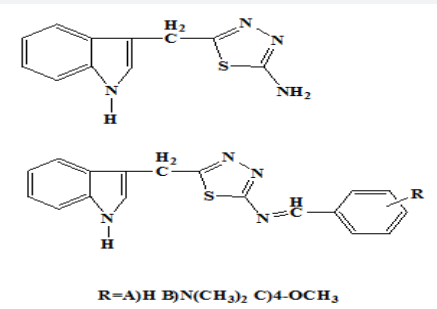

Figure 66: Indole thiadiazole and formazone derivatives.

\section{Antioxidant activity}

Valentina et al. [72], (2009) have synthesized Some substituted 1,2,4 - triazo-5-thione Schiff base and studied their antioxidant activity (Figure 67).

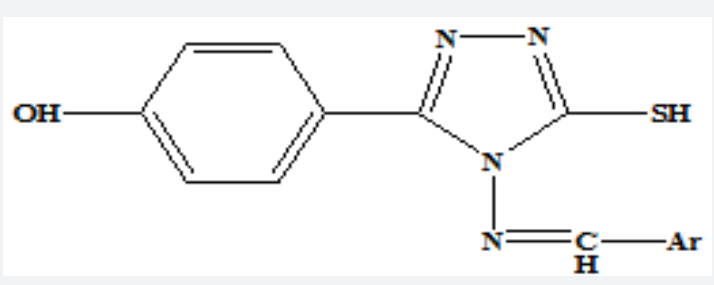

Figure 67: Substituted 1,2,4 - triazo-5-thione Schiff base.

\section{Anti-diabetic activity}

Racanska et al. [73], (2006) have studied the anti diabetic activity of some Copper Schiff base complexes on Alexon-induced diabetic method (Figure 68).

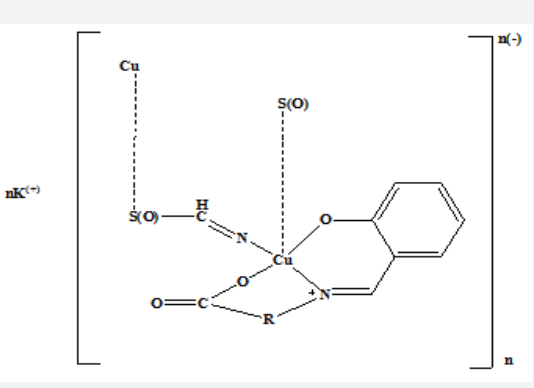

Figure 68: Copper Schiff base complexes.

\section{Anti-hypertensive activity}

Shreenivas MT et al. [74], (2009) have reported Many Schiff bases and they were prepared by condensation reaction of nitro compound containing biphenyl ether amines with aromatic aldehydes and ketone derivatives and thiazolidines were prepared by Schiff base with a thiglycolic acid. The synthesized compounds were screened for AT1 Angiotensin (An II) Receptor Antagonist activity. The nitro compound containing biphenyl ether Schiff bases and thiazolidines show good activity compared with losartan (Figure 69).

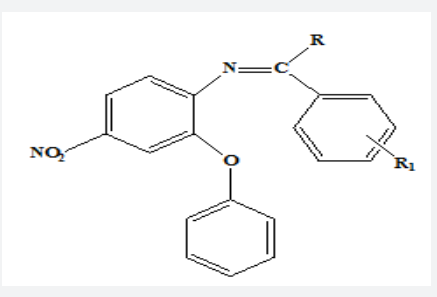

Figure 69: Schiff base derivatives.

\section{Other activity}

Katritzky AN et al. [75], (1995) have synthesized several 1, 3,5 triphenyl formazans using a new methodology. Azo coupling of aryl diazonium salts with aryl aldehyde, aryl hydrazones under mild basic conditions in two-phase liquid- liquid media is efficiently promoted by phase -transfer catalysts (Onium salts or dicyclohexano-18 crown 6) at $-250 \mathrm{oC}$. The condensation of benzaldehyde with phenyl hydrazine followed by phase, transfer catalyzed azo-coupling with phenyl diazonium chloride (one pot procedure) gave 1,3,5 triphenyl formazans in a $54 \%$ yield without isolation of the intermediate benzaldehyde phenyl hydrazone. A double azo-coupling reaction of phenyl diazonium chloride with 9-different $\mathrm{CH}$-active compounds afforded corresponding formazan only in the case of phenyl pyruvic acid. Reaction with malonamide gave 3-carboaomoyl 1,5-diphenyl formazan instead of expected 1,5-diphenyl formazans (Figure 70). 


\section{Organic and Medicinal Chemistry International Journal}

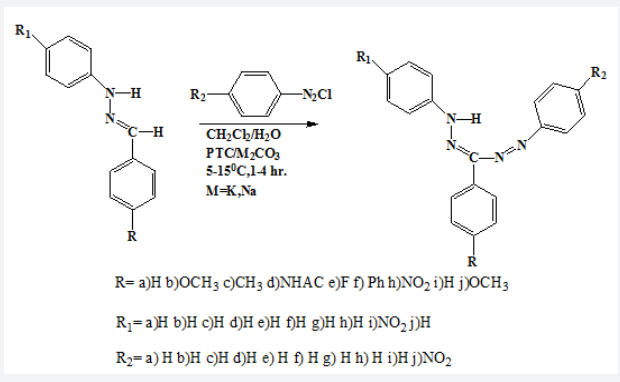

Figure 70: 1, 3, 5 triphenyl formazans.

Khalil RA et al. [76], (2008) have been reported the present paper firstly announces the possibility of using a Schiff base as an acid-base indicator. This surprising phenomenon can be considered as an interest due to the fact that Schiff bases are usually unstable in solutions and definitely undergo hydrolysis. It was found that such a specific observation depends merely upon the chemical structure and type of the substitute of amine that reacts with aldehyde to give the Schiff base (Figure 71).

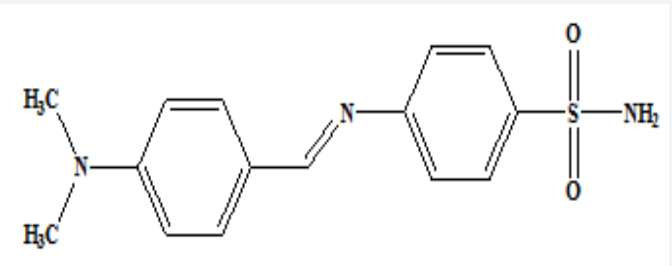

Figure 71: 4-[(4-Dimethylamino-benzylidene)-amino]-benzene sulfonamide.

Arshi N et al. [77], (2009) have reported Non classical methods (water based reaction,

microwave and grindstone chemistry) were used for the preparation of Schiff bases from 3-chloro-4-fluoro aniline and several benzaldehyde. The key raw materials were allowed to react in water, under microwave irradiation and grindstone. These methodologies constitute an energy-efficient and environmentally benign greener chemistry version of the classical condensation reactions for Schiff bases formation (Figure 72).

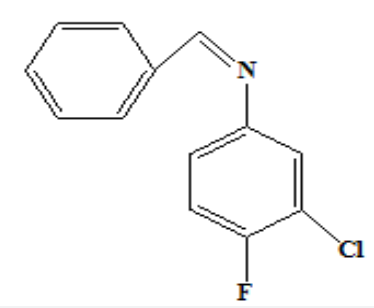

Figure 72: Benzylidene-(3-chloro-4-fluoro-phenyl)-amine.

Mohamed N Ibrahim et al. [78], (2007) have reported Many Schiff bases which were prepared by condensation reaction of certain aromatic amines with aromatic

aldehydes derivatives, then the fluorescence properties of these Schiff bases were

examined in acidic and basic media. It shows that, these compounds can be used

for spectrofluorimetric monitoring of small $\mathrm{pH}$ changes. Hai Jian Yang et al [79], (2002) have described A microwave-assisted preparation of a series of Schiff-base via efficient condensation of salicylaldehyde

and aryl amines without solvent is in high yield as well as environmental

friendship reaction in organic synthesis (Figures $73 \& 74$ ).

\section{Conclusion}

Schiff-base exhibited versatile pharmacological activity, especially wide range of derivatives had shown potent antitumor effects against variety of human cell lines and in vivo animal models. Structure activity relationship of Schiff-base containing derivatives indicated that Schiff-base moiety essential for the pharmacological activity. These results revealed that Schiff-base is an essential pharmacophore for the anticonvulsant activity. We observed that Schiff-base containing derivatives had potent new light to medicinal chemist or scientist to discover new drug. Because of its high efficacy and lower side effect, this ring may be useful tool of new light for modern therapy.

\section{Acknowledgement}

The authors would like to express their gratitude to Babasaheb Bhimrao Ambedkar University (a Central University) Lucknow for providing the research data facilities.

\section{Reference}

1. Nic M, Jirat J, Kosata B eds (2006) Schiff baseIUPAC Compendium of Chemical Terminology. DOI:10.1351/goldbook.S05498. ISBN 096785 9-8.

2. Nic M, Jirat J, Kosata B eds (2006) azomethines. IUPAC Compendium of Chemical Terminology. DOI:10.1351/goldbook. A00564. ISBN 0-9678550-9-8.

3. Nic M, Jirat J, Kosata B eds (2006) anils. IUPAC Compendium of Chemical Terminology (DOI:10.1351/goldbook.A00357. ISBN 0-9678550-9-8.

4. Schiff H (1846) Arm Chem 137: 118.

5. Da Silva CM, Da Silva DL, Modolo LV, Rosemeire B Alves, Maria A de Resende, et al. (2011) Schiff bases: A short review of their antimicrobial activities. J of adv res 2(1): 1-8.

6. Jarrahpour A, A M Zarei (2004) Synthesis of 2-(\{[4-(4-\{[(E)-1-(2hydroxy-3-methoxyphenyl) methylidene amino\} phenoxy) phenyl imino\}methyl)- 6 -methoxyl phenol. MolbankM352. ISSN 1422-8599. Retrieved February 22.

7. Tim Soderberg (2010) Organic Chemistry With a Biological Emphasis. University of Minnesota Morris.

8. Biochemistry dictionary (2012) Jeff D Cronk, Gonzaga University. 


\section{Organic and Medicinal Chemistry International Journal}

9. PG Cozzi (2004) Metal-Salen Schiff base complexes in catalysis: practical aspects. Chemical Society Reviews 33: 410-421.

10. DH Won, D W Yoon, S J Hong, C H Lee, Jonathan L Sessler, et al. (2006) Synthesis and Structure of Non-aromatic Porphyrinoid Schiff-base Macro cycles Bearing Thiophene. Bull Korean Chem Soc 27(6): 925

11. MN Ibrahim, S E A Sharif (2007) Synthesis, characterization and use of Schiff bases as fluorimetric analytical reagents. E-Journal of Chemistry 4(4): 531-535.

12. K B Gudasi, G S Nadagouda, T R Goudar (2006) Journal Indian Chem Soc 83: 376

13. P G More, B N Muthal, A S Lawand (2006) Journal Indian Chem Soc 83: 36.

14. D Kuklkarni, S A Patil, P S Badami (2009) Electrochemical Properties of some Transition Metal Complexes: Synthesis, Characterization and In-vitro antimicrobial studies of $\mathrm{Co}(\mathrm{II}), \mathrm{Ni}(\mathrm{II}), \mathrm{Cu}(\mathrm{II}), \mathrm{Mn}(\mathrm{II})$ and $\mathrm{Fe}(\mathrm{III})$ Complexes. Int J Electrochem Sci 4: 717-729.

15. N Raman, V Muthuraj, S Ravichandran, A Kulandaisamy (2003) Synthesis, characterization and electrochemical behaviour of $\mathrm{Cu}(\mathrm{II})$, Co(II), Ni(II) and Zn(II) complexes derived from acetyl acetone and p-anisidine and their antimicrobial activity. Indian Acad Sci (Chemi. Sci) 115(3): 161-167.

16. PAM Farias, M B R Bostos (2009) Electrochemical Behavior of Copper(II) salen in Aqueous Phosphate Buffer at the Mercury Electrode. Int J Electrochem Sci 4: 458-470.

17. Sheikhshoaie, S Saeedina (2010) the Arbian Journal for Science and Engineering 35: 53.

18. W T Gao, Z Zheng (2002) Synthetic Studies on Optically Active Schiffbase Ligands Derived from Condensation of 2-Hydroxyacetophenone and Chiral Diamines. Molecules 7(7): 511-516.

19. T Uchida, T Katsuki (2001) Tetrahedron Letters 42: 6911-6914.

20. Watanabe, T Uchida, K Ito, T Katsuki (2002) Tetrahedron Letters 43: 4481-4485.

21. DR Reddy, ER Thornton (1992) A very mild, catalytic and versatile procedure for $\alpha$-oxidation of ketone silyl enol ethers using (salen) manganese(III) complexes; a new, chiral complex giving asymmetric induction. A possible model for selective biochemical oxidative reactions through enol formation. Journal of Chemical Society Chemica Communication 2: 172-173.

22. A Wald mar, TF Rainer, RS Viet, RS M Chantu (1998) Journal of American Chemical Society 120: 708-714

23. K Nakajima, K Kojima, T Aoyama, J Fujita (1986) Chemistry Letters 1483-1486

24. H Nishikori, C Ohta, T Katsuki (2000) Synlett 1557-1560.

25. T Uchida, R Irie, T Katsuki (1999) Chiral (ON) Ru-salen catalyzed cyclopropanation: High cis- and enantio-selectivity. Synlett 7: 11661168.

26. T Katsuki (2004) Unique asymmetric catalysis of cis- $\beta$ metal complexes of salen and its related Schiff-base ligands. Chemical Society Reviews 33: $437-444$.

27. SH Zhao, PR Ortiz, BA Keys, KG Davenport (1996) Tetrahedron Letters 2725.

28. RG Cavell, K Aparna, RP Kamalesh Babu, Q Wang (2002) Journal of Molecular Catalysis A Chemical 137-143.

29. GJP Britovsek, VC Gibson, BS Kimberly, PJ Maddox, SJ Mc Tavish, et al. (1998) Novel olefin polymerization catalysts based on iron and cobalt Chemical Communications 7: 849-850.
30. GJP Britovsek, VC Gibson, DF Wass (1999) The Search for NewGeneration Olefin Polymerization Catalysts: Life beyond Metallocenes. Angewandte Chemie International Edition 38(4): 428-447.

31. S Matsui, T Fujita (2001) Catalysis Today 63-73.

32. Y Nakayama, H Bando, Y Sonobe, T Fujita (2004) Olefin polymerization behavior of bis(phenoxy-imine) $\mathrm{Zr}$, Ti, and $\mathrm{V}$ complexes with $\mathrm{MgCl}_{2}$ based co catalysts. Journal of Molecular Catalysis A Chemical 213910: 141-150.

33. R Souane, F Isel, F Peruch, PJ Lutz. (2002) Pyridine bis(imine) cobalt or iron complexes for ethylene and 1-hexene (co)polymerization. Comptes Rendus Chimie 5(1): 43-48.

34. G Venkatachalam, R Ramesh (2005) Ruthenium(III) Schiff base complexes of [ONNO]-type mediated transfer hydrogenation of ketones. Inorganic Chemistry Communications 8(11): 1009-1013.

35. G Venkatachalam, R Ramesh (2006) Ruthenium(III) bis-bidentate Schiff base complexes mediated transfer hydrogenation of imines. Inorganic Chemistry Communications 9(7): 703-707.

36. Sondhi MS, Singh N, Kumar, Lozach 0, Meijer L (2006) A. Synthesis, anti-inflammatory, analgesic, and kinase (CDK-1, CDK-5 and GSK-3) inhibitionactivity evaluation of benzimidazole/benzoxazole derivatives and some Schiff bases. BioorgMed Chem 14(11): 3758-3765.

37. Chinnasamy RP, Sundararajan R, Govindraj S (2010) Synthesis characterization and analgesic activity of novel Schiffbase of isatin derivatives. J Adv Pharm Tech Res 3: 342-347.

38. Bhandari SV, Bothara KG, Raut MK, Patil AA, Sarkate AP, et al. (2008) Med Chem 16: 1822

39. Bawa S, Kumar S (2009) Synthesis of Schiff's bases of 8-methyltetrazolo[1,5-a]quinoline as potential anti-inflammatory and antimicrobial agents. Ind J Chem 48B: 142-145.

40. Lima PC, Lima LM, Silva KC, Leda PH, Miranda ALP, et al. (2000) Synthesis and analgesic activity of novel N-acylarylhydrazones and isosters, derived from natural safrole. Euro J Med Chem 35(2): 187-203.

41. Panneerselvam P Priya GM, Kumar NR, Saravanan G (2009) Synthesis and Pharmacological Evaluation of Schiff Bases of 4-(2-Aminophenyl)Morph lines. Ind J Pharm Sci 71(4): 428-432.

42. N Raman, J Dhaveethu Raja, A SakthivelJ (2007) Synthesis, spectral characterization of Schiff base transition metal complexes: DNA cleavage and antimicrobial activity studies Chem Sci 119(4): 303-310.

43. G Nageswara Reddy et al, (2011) IJSID 1(3): 372-385.

44. Yogendra K, Mahadevan K M, Madhusudhana N, Suneel Naik, Gopalappa H (2011) Photocatalytic Decolorization of Coralene Dark Red 2B Azo Dye by Using Calcium Zincate Nanoparticles in Presence of Natural Sunlight. International Conference on Chemistry and Chemical Process, IACSIT press, Singapore IPCBEE Vol 10.

45. Kucukguzel SG, Oruc EE, Rollas S, Sahin F, Ozbek A (2002) Synthesis, characterisation and biological activity of novel 4-thiazolidinones, 1,3,4-oxadiazoles and some related compounds. Eur J Med Chem 37(3): 197-206.

46. Mamolo MG, Falagiani V, Zampieri D, Vio L, Banfi E, Scialino G, et al. (2003) Synthesis and antimycobacterial activity of (3,4-diaryl-3Hthiazol-2-ylidene)-hydrazide derivatives. Il Farmaco 58(9): 631-637.

47. NGU Sari (2003) journal of science 16(2): 283.

48. T D Thangadurai, SK Ihm (2003) j Ind Eng Chem 9: 563.

49. S Baluja, A Solanki, N Kachhadia (2006) Evaluation of biological activities of some Schiff bases and metal complexes. journal of the Iranian Chemical Society 3(4): 312-317.

50. C Spinu, M Pleniceanu, C Tigae (2008) Biologically Active Transition 


\section{Organic and Medicinal Chemistry International Journal}

Metal Chelates with a 2-Thiophenecarboxaldehyde-Derived Schiff Base: Synthesis, Characterization, and Antibacterial Properties. Turk J Chem 32: 487-493.

51. R Nair, A Shah, S Baluja, S Chanda, (2006) Synthesis and antibacterial activity of some Schiff base complexes. J Serb Chem Soc 71(7): 733-744.

52. F A Morad, M M EL Ajaily, S B Gweirif (2007) Journal of Science and its Application 1: 72.

53. Faizul A, S Satendra, K S Lal, P Om (2007) Synthesis of Schiff bases of naphtha[1,2-d]thiazol-2-amine and metal complexes of 2-(2'-hydroxy) benzylideneaminonaphthothiazole as potential antimicrobial agents. Journal of University Sciences B 8(6): 446-452.

54. N Raman, JD Raja, A Sakthivel (2007) Synthesis, spectral characterization of Schiff base transition metal complexes: DNA cleavage and antimicrobial activity studies. J Chem Sci 119(4): 303-310.

55. E A Elzahany, KH Hegab, S K H Khalil, K N S Youssef (2008) Synthesis, Characterization and Biological Activity of Some Transition Metal Complexes with Schiff Bases Derived from 2-Formylindole Salicylaldehyde, and N-amino Rhodanine. Australian journal of Basic and Applied Science 2(2): 210-220.

56. Desai RM, Desai JM, Shah VH (1999) Synthesis and antimicrobial profile 1,3,4 oxadiazoles, sulphonamides,5-imidazolinones, azomethines,4thiazolidinones,2-azetidinones and formazans and tetrazolium chlorides. Ind J Het Chem 8(4): 329-334.

57. Desai KG, Desai KR (2005) Synthesis of some novel pharmacologically active Schiff bases using microwave method and their derivatives formazans by conventional method. Ind J Chem 44B(10): 2097-2101.

58. Pandey VK, Negi HS (1999) Synthesis of1-(2'-aryl-4'-oxo(3H) quinazolyl)-3-aryl-5phenyl-formazans as potential anti-viral agents. Indian Drugs 36(1): 37-40.

59. Wadher SJ, Puranik MP, Karande NA, Yeole PG (2009) Synthesis and Bio logical Evaluation of Schiff base of Dapsone and their derivative as Antimicrobial agents. International Journal of Pharm Tech Research 1(1): 22-33.

60. Mamolo MG, Falagiani V, Zampieri D, Vio L, Banfi E, et al. (2003) Synthesis and antimycobacterial activity of (3,4-diaryl-3H-thiazol-2ylidene)-hydrazide derivatives. Il Farmaco 58(9): 631-637.

61. Sinha N, Jain S, Tilekar A, Upadhayaya RS, Kishore N, et al. (2005) Synthesis of isonicotinic acid $\mathrm{N}^{\prime}$-arylidene-N-[2-oxo-2-(4-arylpiperazin-1-yl)-ethyl]-hydrazides as antituberculosis agents. Med Chem Lett 15(6): 1573-1576.

62. Sriram D, Yogeeswari P, Devakaram RV (2006) Synthesis, in vitro and in vivo antimycobacterial activities of diclofenac acid hydrazones and amides. Bio org Med Chem 14(9): 3113-3118.

63. M J Hearn, M H Cynamon (2004) Design and synthesis of antituberculars: preparation and evaluation against Mycobacterium tuberculosis of an isoniazid Schiff base. Journal of Antimicrobial Chemotherapy 53: 185191.

64. Demirbas N, Karaoglu S, Demirbas A, Sancak K (2004) Synthesis and antimicrobial activities of some new 1-(5-phenylamino-[1,3,4] thiadiazol-2-yl)methyl-5-oxo-[1,2,4]triazole and 1-(4-phenyl-5- thioxo-[1,2,4]triazol-3-yl)methyl-5-oxo- [1,2,4]triazole derivatives. Eur J Med Chem 39(9): 793-804

65. Terzioglu N, Gursoy A (2003) Synthesis and anticancer evaluation of some new hydrazone derivatives of 2,6-dimethylimidazo[2,1-b][1,3,4] thiadiazole-5-carbohydrazide. Eur J Med Chem 38(7-8): 781-786.

66. Kamel MM, Ali HI, Anwar MM, Mohamed NA, Soliman AM (2010) Synthesis, antitumor activity and molecular docking study of novel Sulfonamide-Schiff's bases, thiazolidinones, benzothiazinones and their C-nucleoside derivatives. Eur J Med Chem 45(2): 572-580.

67. Gursoy E, Guzeldemirci Ulusoy N (2007) Synthesis and primary cytotoxicity evaluation of new imidazo[2,1-b]thiazole derivatives. Eur J Med Chem 42(3): 320-326.

68. F Shabani, L A Saghatforoush, S Ghammamy (2010) Synthesis, characterization and anti-tumour activity of iron(III) Schiff base complexes with unsymmetric tetradentate ligands. Bull Chem. Soc. Ethiop 24(2): 193-199.

69. Ragavendran JV, Sriram D, Patel SK, Reddy IV, Bharathwajan N, et al. (2007) Design and synthesis of anticonvulsants from a combined phthalimide-GABA-anilide and hydrazone pharmacophore. Eur J Med Chem 42(2): 146-151.

70. Dimmock JR, Vashishtha SC, Stables JP (2000) Anticonvulsant properties of various acetylhydrazones, oxamoylhydrazones and semicarbazones derived from aromatic and unsaturated carbonyl compounds. Eur J Med Chem 35(2): 241-248.

71. Archana, Srivastava VK, Kumar A (2003) Synthesis of newer indolyl thiadiazoles and thiazolidinones and formazansas potent anticonvulsant agents. Ind J Pharm Sci 65(4): 358-362.

72. Valentina P, Ilango K, Deepthi M, Harusha P, Pavani G, et al. (2009) Antioxidant Activity of Some Substituted 1, 2, 4 - Triazo-5-thione Schiff base. Pharm Sci Res 1(2): 74-77.

73. E Racanska, O Svajlenova, J Valuska, J Vanco, Tomas L (2006)III.

74. Shreenivas MT,Chetan BP,BhatAR (2009) Synthesisand Pharmacological Evaluation of Certain Schiff Bases and Thiazoldine Derivatives as AT1 Angiotension-II(AII) Receptor Antagonists. Journal of Pharmaceutical Science and Technology 1: 88-94.

75. Katritzky AN, BelyakovSA, Dai Cheng, Dupont DurstH (1995) Synthesis of formazans under phase-transfer conditions. Synthesis5:577-581.

76. RA Khalil, AH Jalil, AY Abd Alrazzak (2008) Application of a Schiff Base De rived from Sulfanilamide as an Acid-Base Indicator. J Iran Chem Soc 6(2): 345-352.

77. Arshi N, Mohd S, Arikatla V Rao, Daya S Seth, Nawal K Sharma (2009) Synthesis of SchiffBasesviaEnvironmentallyBenignandEnergy-EfficientGreenerMethodologies. E-Journal of Chemistry 6(S1), S75-S78.

78. Mohamed N Ibrahim, Salah E A Sharif (2007) Synthesis, Characterization and of Use Schiff Bases as Fluorimetric Analytical Reagents. E-Journal of Chemistry 4(4): 531-535.

79. Hai Jian YANG, Wen Hua SUN, Zi Long LI, Zhi MA (2002) The Rapid Synthesis of Schiff-Base without Solvent under Microwave Irradiation. Chinese Chemical Letters 13:3-6. 
(C) Co Commons Attribution 4.0 License (c) DY: 10.19080/OMCIJ.2017.01.555564
Your next submission with Juniper Publishers will reach you the below assets

- Quality Editorial service

- Swift Peer Review

- Reprints availability

- E-prints Service

- Manuscript Podcast for convenient understanding

- Global attainment for your research

- Manuscript accessibility in different formats (Pdf, E-pub, Full Text, Audio)

- Unceasing customer service

Track the below URL for one-step submission https://juniperpublishers.com/online-submission.php 